\title{
Uma boa qualidade de vida no trabalho gera bons resultados
}

\author{
A good quality of life at work generates good results \\ Una buena calidad de vida en el trabajo genera buenos resultados
}

Recebido: 28/06/2021 | Revisado: 04/07/2021 | Aceito: 07/07/2021 | Publicado: 18/07/2021

\author{
Layane Aguiar da Silva Oliveira Jucá \\ ORCID: https://orcid.org/0000-0001-8509-9895 \\ Grupo Educacional FAVENI, Brasil \\ E-mail: layaneaguiar@hotmail.com
}

\begin{abstract}
Resumo
Atualmente $\mathrm{o}$ ato de trabalhar se torna cada vez mais necessário na vida da maioria da população. As pessoas buscam um meio de suprir suas necessidades, que acabam aumentando com o tempo. O cidadão tem o conhecimento de que é preciso bastante esforço para aprender, trabalhar, e ser assim um futuro profissional engajado concluindo seus objetivos com sabedoria e bom senso, seguro de si e fazendo o suficiente para ter eficiência em seu trabalho, ajudando da melhor maneira possível, a fim de conquistar um futuro promissor. Este artigo tem a finalidade de apresentar benefícios de um profissional motivado para assim lidar com as adversidades da realidade atual, feito a partir de pesquisas bibliográficas. Seus objetivos são: visualizar a qualidade de vida da empresa como uma motivação para profissionais no ambiente de trabalho. Como conclusão observa-se o fato de que um ambiente ideal e um profissional seguro formam um bom convívio social e alavancam para um futuro promissor.
\end{abstract}

Palavras-chave: Qualidade de vida no trabalho; Motivação; Eficiência.

\begin{abstract}
Currently, the act of working is becoming more and more necessary in the lives of the majority of the population. People look for a way to meet their needs, which end up increasing over time. Citizens are aware that it takes a lot of effort to learn, work, and thus be an engaged professional future, completing their goals with wisdom and common sense, confident and doing enough to be efficient in their work, helping in the best way. possible in order to achieve a promising future. This article aims to present the benefits of a motivated professional to deal with the adversities of the current reality, based on bibliographic research. Its objectives are: to visualize the company's quality of life as a motivation for professionals in the workplace. In conclusion, it is observed that an ideal environment and a safe professional form a good social life and leverage for a promising future.
\end{abstract}

Keywords: Quality of life at work; Motivation; Efficiency.

\begin{abstract}
Resumen
Actualmente, el acto de trabajar es cada vez más necesario en la vida de la mayoría de la población. La gente busca la forma de satisfacer sus necesidades, que acaban aumentando con el tiempo. Los ciudadanos son conscientes de que se necesita mucho esfuerzo para aprender, trabajar y así ser un futuro profesional comprometido, cumpliendo sus objetivos con sabiduría y sentido común, confiados y haciendo lo suficiente para ser eficientes en su trabajo, ayudando de la mejor manera posible. para lograr un futuro prometedor. Este artículo tiene como objetivo presentar los beneficios de un profesional motivado para hacer frente a las adversidades de la realidad actual, a partir de la investigación bibliográfica. Sus objetivos son: visualizar la calidad de vida de la empresa como motivación para los profesionales en el lugar de trabajo. En conclusión, se observa que un entorno ideal y un profesional seguro conforman una buena vida social y apalancamiento para un futuro prometedor.
\end{abstract}

Palabras clave: Calidad de vida em el trabajo; Motivacion; Eficiencia.

\section{Introdução}

Conviver é uma tarefa complicada ainda nos dias de hoje, pois o ser humano nem sempre é capaz de aceitar outras opiniões, outras vivências ou até mesmo outras pessoas. Conviver é um processo de adaptação, mas que a cada dia sofre mais alterações. Todo o mundo muda, as pessoas se transformam, e o ambiente também.

Trabalhar com outras pessoas certas vezes gera um desconforto, pois existem opiniões paralelas ainda que pretendam chegar a um objetivo comum. Era da mesma forma que acontecia no colégio, os grupos eram formados aleatoriamente e nem 
todos concordavam com isso. Hoje, você adulto, passa por isso no ambiente de trabalho. A Qualidade de Vida no Trabalho é essencial para trazer bons resultados.

Muitas pessoas pensam que ao passar da etapa de conseguir um emprego não terão mais dificuldades, como se "tudo fossem flores", mas não é dessa forma que acontece. O período de adaptação no emprego também é difícil, e nesse momento algumas pessoas desistem. Por isso é importante se sentir bem no local em que irá trabalhar.

Para o autor Spector (2003), a motivação é um conceito psicológico que, apesar de intensamente discutido há pelo menos um século, ainda é de difícil definição. Geralmente descrita como um estado interior que induz a uma ação, está relacionada ao desejo de adquirir ou alcançar algum objetivo constituindo, portanto, a força que estimula a pessoa a agir. Dessa forma, a motivação resulta da relação do indivíduo com o ambiente, que se expressa fundamentalmente como a satisfação e comprometimento com o trabalho. Spector

Segundo Valoto (1999), o funcionário precisa de um ambiente propício para demonstrar sua capacidade de realização de tarefa. Uma máquina quebrada, instrumentos e ferramentas obsoletos levam à baixa produtividade e consequentemente a desmotivação. As condições de higiene e espaço físico de trabalho, alimentação, pausas para repouso, todos esses aspectos interferem no nível de motivação.

Seria ótimo iniciar o emprego já sentindo o ambiente calmo, respeitável, com boas condições de higiene, socialização, funcionários, horário de expediente. Tudo já conversado para que o funcionário desenvolva a eficiência em seus projetos atuais e futuros.

De acordo com Bergamini (1999), nas organizações, o salário é o fator motivacional mais utilizado, mas administrar usando recompensas não é tão previsível quanto se possa desejar. Estudos mostram que o grau de satisfação após o aumento salarial era intenso, mas de curta duração.

Para Pereira (2011), Qualidade de Vida ainda não foi bem conceituada e definida quanto às quais fatores a influenciam, no princípio pensava-se que era somente a remuneração e as conquistas profissionais que a afetam, mas com o passar do tempo novos fatores passaram a ser avaliados como grau de satisfação, satisfação pessoal, local de trabalho com condições adequadas, entre outros.

O objetivo do artigo é visualizar a qualidade de vida da empresa como uma motivação para profissionais no ambiente de trabalho.

Este se justifica ao apresentar benefícios de um profissional motivado para assim lidar com as adversidades da realidade.

\section{Metodologia}

O trabalho em questão foi feito no primeiro semestre de 2021 a partir de pesquisas bibliográficas que definem a qualidade de vida, benefícios e condições em que os funcionários podem se encontrar nesta situação para assim definir o que pode ser feito pela empresa ou por eles mesmos para sanar tais dificuldades e chegar a um propósito/objetivo comum.

\section{Resultados e Discussão}

Com a disputa existente no mercado de trabalho as empresas têm se empenhado a focar em mais trabalho e mais lucros, sobrecarregando seus funcionários com tarefas diárias que precisam estar prontas ao final de certo tempo. Elas contam com uma quantidade maior de funcionários a fim de sanar as necessidades e atingir seus objetivos. Para que isso funcione é necessário que apesar das diferenças, todos trabalhem por um bem comum. (Ribeiro \& Santana, 2015). 
De acordo com Ribeiro e Santana (2015), (2010) a QVT é um constructo complexo que envolve uma constelação de fatores, como: Satisfação com o trabalho executado, as possibilidade de futuro na organização, o reconhecimento pelos resultados alcançados, o salário percebido, os benefícios auferidos, o relacionamento humano dentro da equipe e da organização, o ambiente psicológico e físico de trabalho, a liberdade de atuar e responsabilidade de tomar decisões e a possibilidade de estar engajado e de participar ativamente na organização.

Todos esses são exemplos de melhorar o convívio e as ações no ambiente de trabalho, para que não fique tão cansativo para a equipe.

A seguinte figura mostra uma reunião de equipe para conversar sobre situações da empresa.

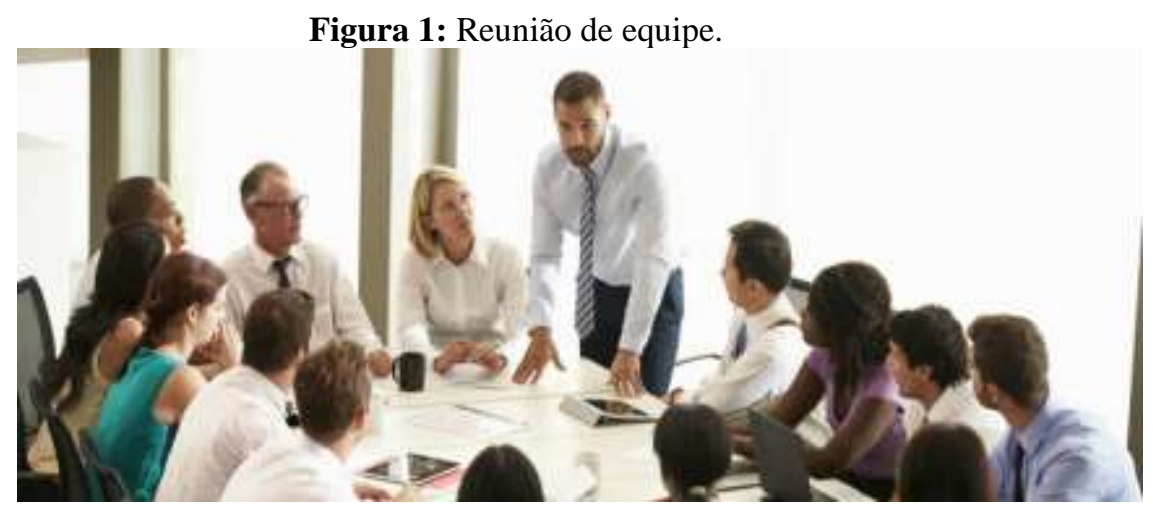

Fonte: Gympass (2016).

Algumas pessoas buscam um emprego baseado na formação acadêmica que tiveram. Isso por muitas vezes é difícil, pois o mercado de trabalho está cada vez mais exigente, então é necessário que se empenhem cada vez mais.

É importante respeitar as opiniões alheias e impor as suas quando necessário/solicitado, assim todos serão ouvidos e uma ideia pode alcançar um propósito ideal.

Uma boa equipe trabalha unida e soma seus esforços e deveres aos dos outros. Há dias em que esse espírito de camaradagem não funciona, sendo assim necessário buscar incentivos, motivações e ajuda necessária a cada tipo de situação.

Como diz Chiavenato (1999):

Um bom lugar para trabalhar é aquele em que você confia nas pessoas para quem trabalha, sente orgulho do que faz e gosta dos colegas de trabalho. A confiança existe quando a direção da empresa é digna de crédito, respeita você e o trata de maneira justa. Também é importante sentir orgulho do seu trabalho. (Chiavenato, 1999, p. 36)

É necessário também que haja uma boa equipe de RH na empresa, com profissionais voltados a área da educação, saúde, incentivo; pois a empresa deve oferecer boas condições de trabalho para seus funcionários. A produtividade depende também da saúde mental e motivação dos trabalhadores, a fim de estabelecer um bem comum favorável a todos na equipe. (Chiavenato, 1999)

Algumas pessoas trabalhando somente por necessidade, sem gostar do trabalho que fazem acabam sofrendo desânimo e falta de estímulo e isso torna o trabalho automático e cansativo. É necessário haver uma boa relação entre empregados e empregadores, para tentar amenizar tal situação. Quando ambas as partes do desenvolvimento do serviço agem juntas é mais fácil chegar à mesma finalidade. (Bonfante, Oliveira \& Nardi, 2015).

A figura a seguir mostra uma funcionária desmotivada por seu trabalho feito de forma automática. 
Figura 2: Funcionária desmotivada no trabalho.

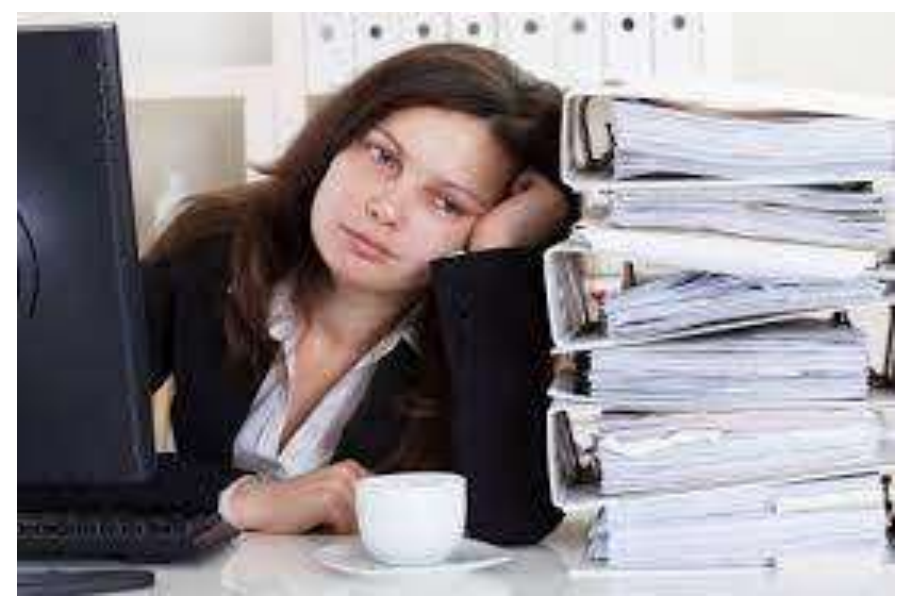

Fonte: Coelho (2019).

De acordo com Chiavenato (1999):

$\mathrm{O}$ século XX trouxe grandes mudanças e transformações que influenciaram poderosamente as organizações, a sua administração e a seu comportamento. É um século que pode ainda ser definido como o século das burocracias ou o século das fábricas, apesar da mudança que se acelerou nas últimas décadas. E, sem dúvida alguma, as mudanças e transformações que nele aconteceram marcaram indelevelmente a maneira de administrar as pessoas. (Chiavenato, 1999, p.27)

É notória a existência de insatisfação com o ambiente de trabalho por boa parte da população. Empregos insalubres, com cargas horárias pesadas, salário mínimo, má gestão, falta de benefícios e incentivos. Tudo isso faz com que o funcionário fique desanimado, não produzindo bem. Isso afeta sua saúde mental, sua vida em casa, sua socialização. O tipo de tarefa que ele poderá ter ao longo do dia também é um agravante para desmotivação. É um ciclo. E dependendo da rotina esse ciclo pode incidir em um bom ou ruim resultado.

Campos (2016) e Ferreira (2016) salientam que o desgaste físico e psicológico, a baixa autoestima, a pressão por resultados e a insatisfação são aspectos inerentes a esse novo mundo de trabalho, e, dessa forma, a questão da Qualidade de Vida no Trabalho passa a obter destaque e demanda projetos para buscar solução para esses problemas.

Observe o esquema do ciclo motivacional. 
Figura 3: Esquema do Ciclo Motivacional.

\section{CICLO MOTIVACIONAL}

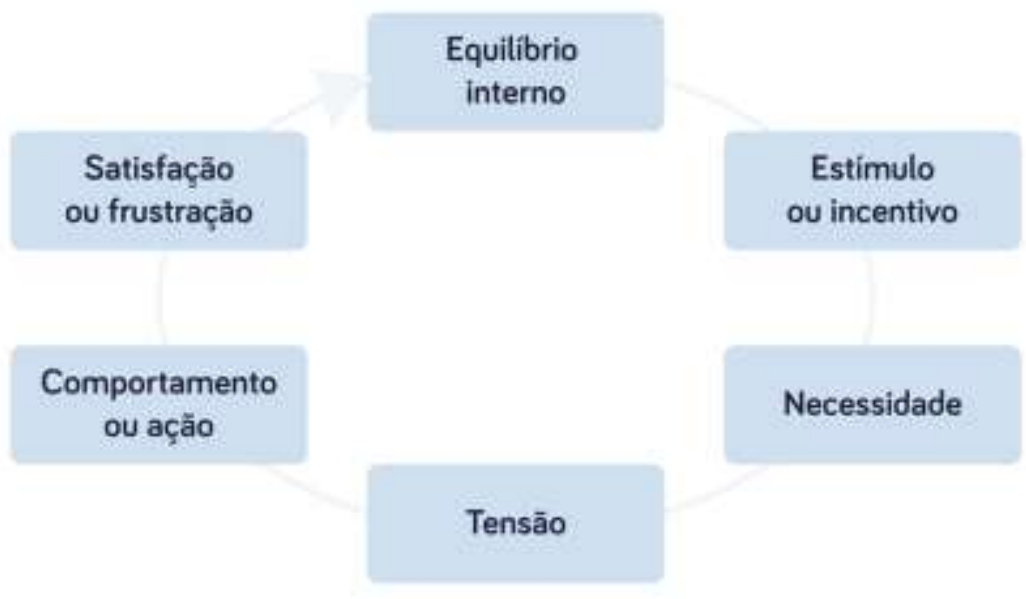

Fonte: Carneiro (2020).

O equilíbrio interno é a normalidade de o funcionário saber o que acontecerá em seu dia; o estímulo ou incentivo é que "aperta o gatilho" e o faz querer fazer algo melhor por estar motivado; a necessidade é entendida com pensamentos de tal funcionário em conseguir ou não atingir sua meta (precisando talvez de treinamento) para progredir; a tensão é ocasionada pela falta desses treinamentos podendo causar estresse; o comportamento é o que o funcionário faz para atingir sua meta; sentindose assim satisfeito (motivado) ou insatisfeito (desmotivado) por ter concluído ou não.

A motivação parte do próprio funcionário é algo pessoal, o que o faz se inserir plenamente em seu trabalho ou não, já o incentivo é algo que a empresa pode fazer por ele, como benefícios de bonificação por venda em uma empresa por exemplo. O tipo de incentivo é relativo, mas é algo que pode ajudar bastante. As empresas que não possuem essa metodologia poderiam ao menos cultivar um ambiente de trabalho saudável com uma boa qualidade de vida para que todos que ali trabalham permaneçam por vontade própria. (Lawler, 1997).

Funcionário motivado demonstra seu bem-estar na figura abaixo.

Figura 4: Funcionário motivado.

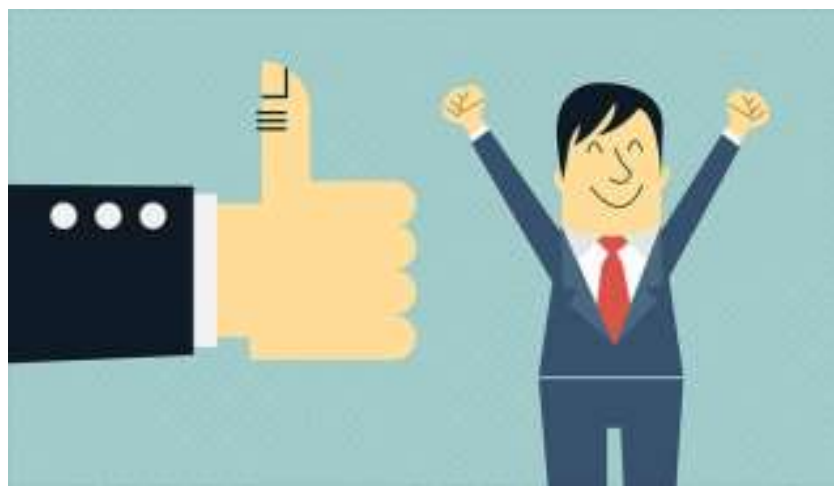

Fonte: Talentos Consultoria (2020). 
Segundo o Dicionário Aurélio, motivação é "ato ou efeito de motivar, de despertar o interesse por algo". E seguindo esta lógica é interessante notar que os seres humanos precisam de um incentivo que o façam agir melhor para cumprir seus trabalhos. As pessoas não podem ser consideradas meras recebedoras de tarefas, geralmente como ordens, e apenas isso. É importante que tais ordens venham com zelo, pois o ser humano é um ser que lida com sentimentos, que precisa de estímulo.

Por exemplo, em uma situação hipotética uma pedagoga responsável pelo serviço de RH em determinada empresa precisa delegar ao funcionário $\mathrm{X}$ a elaboração de um projeto inovador de recrutamento de novos empregados com um curto prazo de uma semana, pois se necessita de maior força de trabalho em pouco tempo, e o projeto anterior está defasado. O funcionário X está com outros trabalhos acumulados e não sabe se dará conta de prosseguir. Há maneiras de incentivá-lo, caso fosse possível, como um período de férias logo após esse serviço, uma bonificação extra, delegar um funcionário Y para auxiliá-lo, entre outros. Não é difícil imaginar formas de incentivo ou motivação no ambiente de trabalho. E sendo possível concretizar valeria muito à pena. (Dicio. Dicionário Online de Português, 2020).

No trabalho de Chiavenato (2000), de acordo com Ribeiro, L., \& Santana, L. (2015), os fatores motivacionais estão sob o controle do indivíduo, pois se relacionam com aquilo que ele faz e desempenha. Envolvem sentimentos de crescimento individual, reconhecimento profissional, auto realização e dependem das tarefas que o indivíduo realiza no seu trabalho.

Pessoas motivadas geram um melhor funcionamento na empresa, maior comprometimento e inovação. Assim esse ciclo continua fazendo bem a todos e na maioria das vezes gerando ótimos resultados. (Talentos Consultoria, 2020).

Alguns pontos da motivação da pessoa em seu ambiente de trabalho é saber o que está fazendo, conhecer o local, gostar do que está fazendo e também a remuneração salarial. É sentir-se acolhido naquele ambiente em que boa parte do tempo será considerado um lar.

No trabalho de Robbins (2005), de acordo com Santos, et al (2016), cada indivíduo precisa ter uma visão bem clara de onde quer chegar e quais suas metas pessoais para que possa trabalhar com determinação e fazer o possível, o que estiver ao seu alcance para alcançar os objetivos e metas, tanto pessoais como os da empresa ou organização a que pertence.

Na figura à seguir há algumas maneiras de motivar funcionários.

Figura 5: Itens de motivação para funcionários.

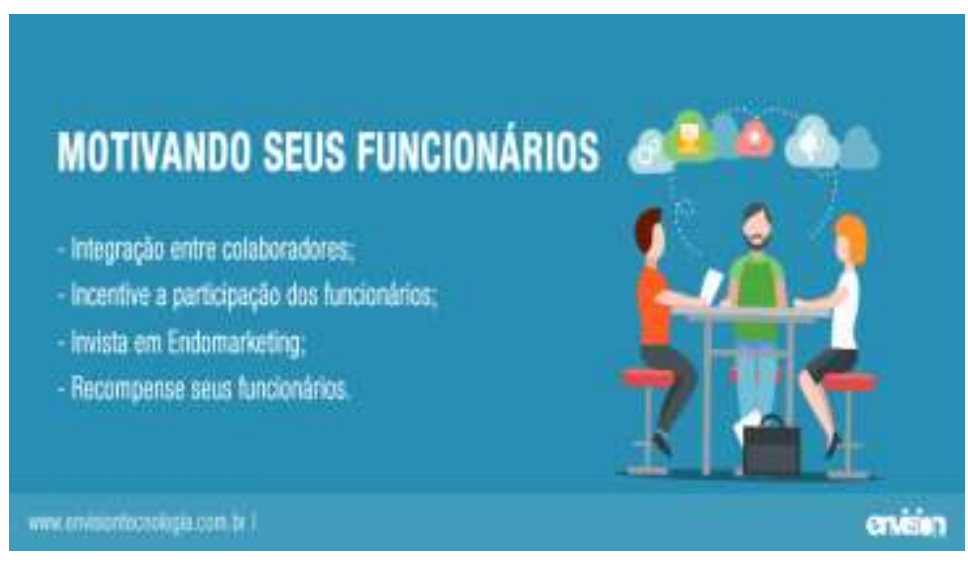

Fonte: Souza (2016).

Como exemplo pode-se citar o trabalho de Walton (1975), segundo Limongi-França (2004):

O trabalho de Walton (1975, apud Limongi-França, 2004, p.34) no campo conceitual, forneceu um modelo de análise de experimentos importantes sobre Qualidade de Vida no Trabalho com oito categorias conceituais como critérios de QVT, incluindo: compensação justa e adequada, condições de trabalho seguras e saudáveis, oportunidades imediatas 
para desenvolver e usar as capacidades humanas, oportunidades futuras para o crescimento contínuo e a garantia de emprego, integração social na organização, constitucionalismo na organização, trabalho e espaço total na vida do indivíduo, e relevância social do trabalho.

Existem muitos pontos negativos em trabalhar com outras pessoas, mas para tentar sanar tais dificuldades, vale a pena se esforçar e tentar garantir um consenso, equilibrando os lados. Nem sempre são fatores grandes que geram o descontentamento por parte do funcionário, mas coisas pequenas que vão se acumulando ao longo do tempo e desencadeando estresse. O ambiente de trabalho pode ser bastante tenso, mas é necessário tentar manter a calma para enfrentar um novo dia. (Marques, 2019).

Chegar em casa e descansar, esquecer os problemas que o fizeram mal. Isso também é qualidade de vida, cuidar do emocional onde estiver. Repor as energias para o dia que virá, relaxar, se cuidar. É o que Marques(2019) aconselha.

Praticar atividades físicas como caminhadas, ler nos intervalos, manter um blog pessoal entre várias outras opções pode contribuir para que você se sinta mais leve e menos estressado no seu dia a dia. Escolha algo que ajude a te manter tranquilo e dedique algum tempo a isso, quando fazemos coisas para nós mesmos não estamos perdendo tempo e sim investindo em qualidade de vida. (Marques, 2019)

Um horário pré-definido também facilita bastante na motivação do trabalhador, pois ele sabe que em determinado horário poderá descansar, mas isso não é tão comum nos dias de hoje. Os horários têm ficado muito flexíveis, esticando-se ao máximo possível para concluir as tarefas do dia.

Algumas empresas que fazem hora-extra pagam esse valor adicional aos funcionários, outras preferem ceder folgas em dias possíveis. E essas já são formas de incentivos que tornam o trabalho mais agradável.

Sobre a alimentação, algumas empresas cedem um cartão de refeição ao funcionário, outras cedem a própria alimentação no estabelecimento, como na figura abaixo, e isso é bastante viável, pois algumas pessoas moram distante do trabalho.

Figura 6: Funcionários alimentando-se na própria empresa que trabalham.

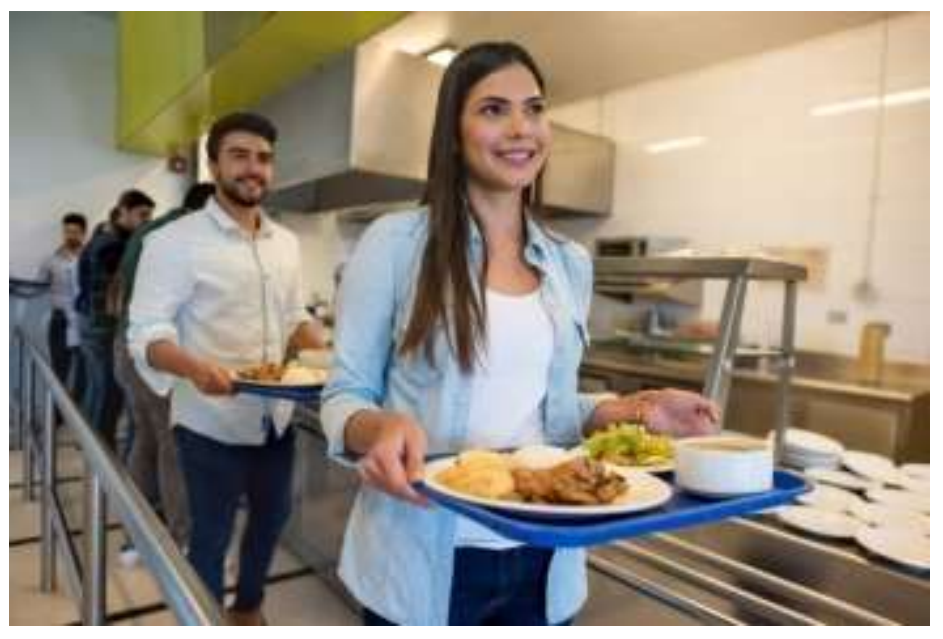

Fonte: Exal (2019).

E em uma empresa que trabalha com vendas? Outra realidade interessante é sobre bonificação para funcionário do mês, por exemplo. Ou comissões para vendas diárias. (Ziemer, 1996). 
Lembrar de aniversários, comemorar vitórias dos objetivos propostos, conversar com a equipe quando tiver problemas, ter um bom líder, estimular o aprendizado, palavras motivadoras, palestras motivacionais. São tantas formas de incentivo e motivação que podem agregar uma boa convivência na relação funcionário e empresa.São propostas a serem estudadas pela equipe de RH da empresa, que no início podem ser consideradas diferentes ou até mesmo prejuízos, mas futuramente serão notadas como investimentos. Funcionários bem tratados agem mais, trabalham melhor. E sim, esses incentivos ajudam muito! (Gympass, 2016)

De acordo com Minayo, Hartz e Buss (2000), a qualidade de vida tem sido igualada a satisfação encontrada na vida familiar, amorosa, social e ambiental; o termo é uma construção social com a marca da relatividade cultural, abrangendo muitos significados, que refletem conhecimentos, experiências e valores de indivíduos e coletividades.

Da Silva, Furtado e Zanini (2015) entendem que a Qualidade de Vida é a forma pela qual se busca aplicar melhores condições para o desenvolvimento do ser humano, seja esta evolução social, mental e emocional. Além disso, a Qualidade de Vida no Trabalho se constitui em uma ferramenta importante para as organizações. Pois ela proporciona maior participação por parte dos colaboradores, criando um ambiente de integração com superiores, com colegas de trabalho e com o próprio ambiente de trabalho, visando, principalmente, dois aspectos importantes que são o bem-estar do trabalhador e a eficácia organizacional.

Fernandes (1996) trata a Qualidade de Vida no Trabalho como ideias associadas às melhorias nas condições físicas, menor jornada de trabalho e maiores salários. Mas também afirma que o enfoque principal é a reformulação da relação do trabalho em si com o empregado, gerando mais eficácia, produtividade e satisfação das necessidades básicas.

A mesma autora, Fernandes (1996) também indica que Qualidade de Vida no Trabalho, é a gestão dinâmica e contingencial de fatores físicos, tecnológicos e sócio-psicológicos que afetam a cultura e renovam o clima organizacional, refletindo-se no bem-estar do trabalhador e na produtividade das empresas, onde a Qualidade de Vida no Trabalho é dinâmica uma vez que tanto as organizações como as pessoas são mutáveis e contingenciais, pois depende da realidade de cada empresa no contexto em que está inserida.

Ferreira, Alves e Tostes (2009) afirmam que para Walton (1973), a Qualidade de Vida no Trabalho depende estritamente do equilíbrio entre trabalho e outras esferas da vida, do papel social da organização e da importância de se conciliar produtividade com QVT.

Para Alves (2011), há pouco tempo, muitas empresas têm buscado incorporar programas padronizados de Qualidad de Vida no Trabalho, mas como não existe um padrão correto, e como uma empresa difere de outra, cada programa deve ter um direcionamento, através de um diagnóstico dos problemas e limitações dos seus recursos, tanto físicos quanto humanos, será possível fazer um planejamento adequado (Alves, 2011).

Já para Venson et al (2013), a Qualidade de Vida no Trabalho só faz sentido quando deixa de ser restrita a programas internos de saúde ou lazer e passa a ser discutida num sentido mais amplo, incluindo a qualidade das relações de trabalho e suas consequências na saúde das pessoas e da organização.

A figura a seguir mostra a alegria de funcionários trabalhando com o que gostam pois se sentem motivados. 
Figura 7: Funcionários motivados e rendendo mais.

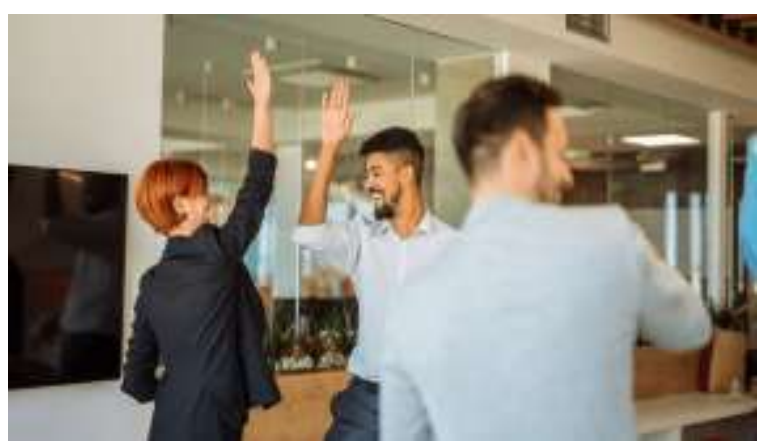

Fonte: Xerpay Blog (2018).

Certamente a realidade que temos é que esses exemplos não se aplicam a todas as empresas, mas que também parte do trabalhador se esforçar e procurar algo que o motive a sempre melhorar. A situação é que as pessoas precisam trabalhar, e caso elas o façam com entusiasmo será ainda melhor.

\section{Conclusão}

Sentir-se bem em um ambiente em que passará boa parte do dia fará toda diferença no desempenho de cada pessoa. Agregando todo o trabalho, esforço e bem-estar, pode-se notar um profissional confiante e eficiente exercendo sua função. Trabalhar em algo que te motiva, com uma equipe que conversa, te escuta e auxilia, conseguindo assim focar no ciclo de motivação, trabalho, eficiência e sucesso, isso sim é recompensador.

Para chegar a essa realidade de emprego ideal, com a melhor qualidade de vida ainda é necessário batalhar muito, mas também é possível começar a se esforçar desde já, e encontrar no trabalho algo que te motive. As empresas precisam enxergar que funcionário satisfeito trabalha melhor, rende mais e o convívio entre eles gera a cada dia objetivos completos de uma forma mais eficiente.

Então trabalhar, confiar, motivar-se e ser mais uma pessoa que pode tornar o ambiente melhor: não é impossível.

O trabalho em questão procurou demonstrar benefícios que uma boa qualidade de vida no ambiente de trabalho pode trazer, fazendo com que os funcionários estejam mais motivados e seus serviços rendendo melhor. Partindo dessa premissa,em futuramente, outros autores podem utilizar esse artigo para demonstrar que não estão sozinhos e que há maneiras de todos motivarem-se para evoluir, do mesmo modo que empresas podem a partir deste, buscar metodologias que funcionem como incentivo para seus funcionários. Estudiosos poderão ter este trabalho como base para metodologias empresariais que podem melhorar a qualidade de vida, fazendo talvez um estudo de caso em empresas da região com a finalidade de saber um pouco sobre a qualidade de vida dos funcionários.

\section{Referências}

Abdala, K., Andrade, A., Júnior, J., Oliveira, D., Rabelo, J. \& Salviano, P. (2020) Descrição dos Fatores Motivacionais no Setor Público: O Caso da Emater Regional Caiapó. Research, Society and Development, 9. https://rsdjournal.org/index.php/rsd/article/view/6697

Alves, C., Correia, A. \& Silva, A. (2019). Qualidade de vida no trabalho (QVT): Um estudo em uma instituição federal de ensino superior. Revista GUAL, 12, 205-227. http://dx.doi.org/10.5007/1983-4535.2019v12n1p205

Alves, E. F. (2011). Programas e ações em qualidade de vida no trabalho: possibilidades e limites das organizações. Revista Eletrônica Fafit/Facic,2(1)

Bergamini, C. (1997). Motivação nas organizações. (4a ed.), Atlas.

Bonfante, J., Oliveira, L., \& Nardi, A. (2015). O impacto da Qualidade de Vida no Trabalho Sobre a Produtividade. Revista Científica Eletrônica UNISEB, vol 06. 114-129. https://aedmoodle.ufpa.br/pluginfile.php/329352/mod_resource/content/1/2A\%20SEMANA\%20\%20Artigo\%20O\%20Impacto\%20da\%20Q ualidade $\% 20 \mathrm{de} \% 20$ Vida\%20no\%20Trabalho\%20sobre\%20a\%20produtividade.pdf 
Borges, G., Stoelben, J. (2019). A Qualidade de Vida no Trabalho da População de uma Pequena Cidade: um Estudo em Dom Pedrito/RS FAMBR, Manaus, 1 , 18-35, http://www.periodicos.ufam.edu.br/ufambr

Campos, N. M. (2016). Qualidade de vida no trabalho dos servidores técnico administrativos do Instituto Federal Sul Rio Grandense lotados em Pelotas (Master's thesis). Universidade Católica de Pelotas.

Carneiro, J. (2020). Você sabe o que é o ciclo motivacional? Veja como funciona o sistema. Website Oito Meia. https://www.oitomeia.com.br/especiais/motiva cional/2020/11/04/voce-sabe-o-que-e-o-ciclo-motivacional-veja-como-funciona-o-sistema-que-promete-te-manter-motivado/.

Chiavenato, I. (1999). Gestão de pessoas. O novo papel dos recursos humanos nas organizações.https://www.academia.edu/36467860/Pdf_lIV RO_gest\%C3\%A3o_de_pesso as_IDALBERTO_CHIAVENATO.

Coelho, A. (2019). Desmotivação do trabalho, o que fazer? Website Ponto RH.https://www.pontorh.com.br/desmotivacao-trabalho-fazer/.

Consultoria, T.(2020). Como o Rh pode motivar funcionários. Website Talentos Consultoria.https://talentosconsultoria.com.br/blog/como-o-rh-pode-motivarfuncionarios/

Da Silva, A. C. C. J., Furtado, J. H., \& Zanini, R. R. (2015). Um estudo sobre a qualidade de vida no trabalho (QVT) e os fatores associados. Iberoamerican. Journal of Industrial Engineering, 7(14), 182-200.

Dicio. Dicionário Online de Português.https://www.dicio.com.br/motivacao/.

Educação, P. (2020). Conceito de motivação: Recursos Humanos. Website Portal Educação. https://siteantigo.portaleducacao.com.br/conteudo/arti gos/educacao/conceito-de-motivacao/62535

Exal. (2019). Excelência em alimentação.Website Exal. https://exal.com.br/tipos-de-servicos-de-alimentacao-nas-empresas-qual-escolher/.

Fernandes, E. C. Qualidade de vida no trabalho: como medir para melhorar. Salvador: Casa da Qualidade Editora Ltda., 1996.

Ferreira, M. C. (2016). Qualidade de vida no trabalho: Uma abordagem centrada no olhar dos trabalhadores (3rd ed.). Paralelo 15.

Ferreira, M. C; Alves, L., \& Tostes, N. (2009) Gestão de Qualidade de Vida no Trabalho (QVT) no serviço público federal: o descompasso entre problemas e práticas gerenciais. Revista Psicologia: Teoria e Pesquisa. 25, 319-327.

Gympass. (2016). A importância de funcionários satisfeitos para o sucesso da sua empresa. Blog Gympass. https://blog.gympass.com/importancia-defuncionarios-satisfeitos-para-o-sucesso-da-sua-empresa/.

Klein, L., Lemos, R. \& Pereira, B. (2019). Qualidade de vida no trabalho: Parâmetros e Avaliação no Serviço Público. Rev. Adm. Mackenzie 20 (3). https://doi.org/10.1590/1678-6971/eRAMG190134

Lawler, E. (1997). Motivação nas organizações de trabalho. Atlas.

Limongi-França, A. (1992). Núcleo de Pesquisas em Gestão da Qualidade de Vida no Trabalho. Website. Núcleo GQVT. http://www.nucleogqvt.com.br/quem-somos/.

Marques, M. (2019). Como manter a calma no trabalho. Website Marcus Marques. http://marcusmarques.com.br/comportamento/como-manter-a-calma-notrabalho/.

Minayo, M. C. D. S., Hartz, Z. M. D. A., \& Buss, P. M. (2000). Quality of life and health: a necessary debate. Ciência \& Saúde Coletiva, 5(1), 7-18.

Pereira, D. L. (2011). Qualidade de vida no trabalho: influências dos avanços tecnológicos (Monografia de pós-graduação). Universidade Tecnológica Federal do Paraná, Ponta Grossa, PR, Brasil.

Ribeiro, L., \& Santana, L. (2015). Qualidade de vida no trabalho: fator decisivo para o sucesso organizacional. Revista de Iniciação Científica, 2. 75-96. https://www.cairu.br/riccairu/pdf/artigos/2/06_QUALIDADE_VIDA_TRABALHO.pdf

Santos, C., Vieira, D., Henke, F., Cichello, N., Baiao, T. \& Cunha, M. (2016). A importância da motivação no ambiente de trabalho. Aten@ Revista Digital de Gestão \& Negócios. Vol 01. - número 0. http://periodicosunimes.unimesvirtual.com.br/index.php?journal=gestaoen egocios\&page=índex

Silva, B., Kaulfluss, M. (2015) Motivação no ambiente de trabalho. Simpósio de Ciências Aplicadas da FAIT. http://fait.revista.inf.br/imagens_arquivos/arquivos_destaque/b1an997j0ojPidX_2017-1-17-19-34-46.pdf

Souza, A. (2016). Motivando seus funcionários. 4 dicas simples para motivar a sua equipe e melhorar o desempenho da empresa. Website Envision Tecnologia. https://www.envisiontecnologia.com.br/motivando-seus-funcionarios-4-dicas-simples-para-motivar-sua-equipe-e-melhorar-o-desempenho-da-suaempresa/.

Spector, P. E. (2003). Psicologia nas organizações. Saraiva.

Valoto, P. (1999) Motivação e autoestima em vendas. Editora Multideia.

Venson, A. B. S., et al. (2013). O recurso mais importante para as organizações são mesmo as pessoas? Revista ADM UFSM, 6, 139-156.

Xerpay Blog. (2018). 4 benefícios da qualidade de vida no trabalho e como incentivá-los.https://xerpay.com.br/blog/beneficios-qualidade-vida-trabalho/.

Ziemer, R. (1996). Mitos Organizacionais: o poder invisível da vida nas empresas. Atlas. 